\title{
Novel targets for anti-inflammatory therapy in inflammatory bowel disease
}

\author{
JOHN L WALLACE PhD
}

JL WALLACE. Novel targets for anti-inflammatory therapy in inflammatory bowel disease. Can J Gastroenterol 1994;8(6):373-378. Until the cause(s) of inflammatory bowel disease are identified, improvements in therapy will likely come from improved anti-inflammatory therapy or improved drug delivery systems. There are many potential targets for anti-inflammatory therapy, including the synthesis of specific inflammatory mediators. This review focuses on the potential for developing therapy aimed at three targets: nerves and neuropeptides; coagulation and thrombosis; and adhesion molecules. In each case, evidence is presented from clinical and/or experimental studies that supports the hypothesis that these are rational targets for anti-inflammatory drug development.

Key Words: Enteric nervous system, Heparin, Inflammatory bowel disease, Integrins, Selectins, Substance P. Thrombosis

\section{Nouvelles cibles du traitement anti-inflammatoire dans la maladie inflammatoire de l'intestin}

RÉSUMÉ : Tant que les causes de la maladie inflammatoire de l'intestin ne seront pas élucidées, les progrès thérapeutiques dans ce domaine ne pourront provenir que de l'amélioration des médicaments anti-inflammatoires ou de leur système d'administration. Les thérapeutiques anti-inflammatoires peuvent viser diverses cibles, y compris la synthèse même de médiateurs spécifiques de l'inflammation. Cet article se penche sur les avantages à tirer d'une thérapeutique à trois visées : les nerfs et les neuropeptides, la coagulation et la thrombose, et finalement, l'adhésivité des molécules. Dans chaque cas, des résultats d'études cliniques ou d'expériences à l'appui, sont présentés pour confirmer l'hypothèse selon laquelle ces cibles sont à explorer dans le contexte de la recherche pour élaborer des thérapeutiques anti-inflammatoires.

Intestinal Diseases Research Group, University of Calgary, Calgary, Alberta

Correspondence and reprints: Dr John L Wallace, Intestinal Diseases Research Group, University of Calgary, Calgary, Alberta. Telephone (403) 220-4539, Fax (403) 270-3353

This paper was presented at the Trends in Inflammatory Bowel Disease Therapy meeting, April 6 to 9, 1994, held in Victoria, British Columbia. This paper has also been published in Sutherland LR, et al, eds. Inflammatory Bowel Disease: Basic Research, Clinical Implications and Trends in Therapy. Boston, Dordrecht and London: Kluwer Academic Publishers, 1994
DVances in the treatment
of inflammatory bowel disease (IBD), at least in the short term, will likely come from improvements in the delivery of existing drugs to the affected region of the intestinal tract, or from improvements in the effectiveness of anti-inflammatory therapy. Over the past decade, much attention has been focused on the prospect of targeting specific inflammatory mediators for the therapy of IBD. For example, it has been suggested that inhibiting the synthesis or actions of leukotrienes $(1,2)$, platelet-activating factor (PAF) $(3,4)$ or interleukin-1 (5) may be rational approaches to the treatment of IBD. It remains to be seen if any of these approaches will lead to significant improvement in IBD therapy. An important question that will be answered by clinical studies is whether it is better to have a highly selective anti-inflammatory drug (ie, one targeted at a single inflammatory mediator) or, because of the redundancy of inflammatory mediators, a less specific anti- inflammatory drug. For example, is the success of glucocorticoids in the treatment of IBD attributable to its lack of specificity (it inhibits the production of many inflammatory mediators and cytokines, blocks expression of adhesion molecules, etc)? 


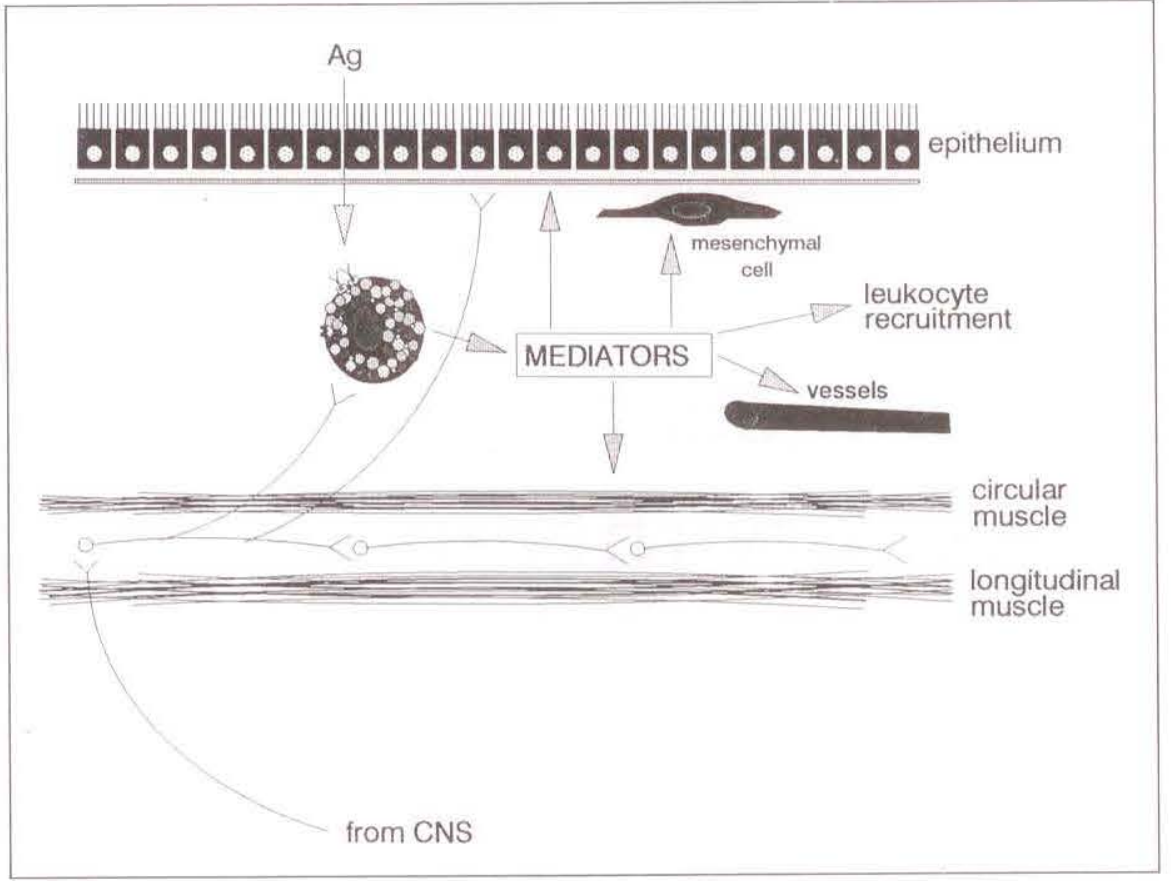

Figure 1) Possible role of enteric and extrinsic neurons in modulating intestinal inflammation. Immunocytes, including mast cells, are in close contact with mucosal neurons and it is possible that neural activation can lead to activation of the immunocytes to release soluble mediators. These mediators exert effects on the epithelium, mesenchymal cells, vasculature and muscle, as well as recruiting granulocytes into the tissue. The nerves can also release chemotactic mediators (eg, substance P). Ag Antigen; CNS Central nervous system

The author reviews the evidence pertinent to three of the possible targets for anti-inflammatory therapy in IBD, which have been explored either in animal models or in small clinical trials: nerves and neuropeptides; coagulation and thrombosis; and adhesion molecules on leukocytes and endothelial cells.

\section{NERVES AND NEUROPEPTIDES}

Among the mediators implicated in the pathogenesis of IBD are the neuropeptides released from enteric and sensory afferent neurons (6) (Figure 1). These peptides, which include substance $P$, vasoactive intestinal polypeptide and calcitonin generelated peptide, have been shown to modulate many aspects of mucosal function, including bloodflow and secretion, and may play a role in the recruitment of granulocytes and lymphocytes (7) and in the modulation of immune function $(8,9)$. Lymphocyte function may also be modulated by neurons within the colonic mucosa since these cells have receptors for a the severity of colonic inflammation in a rat model of chronic colitis. Lidocaine significantly reduced the colonic ulceration and infiltration of granulocytes into the mucosa. These authors pointed out that lidocaine has many anti-inflammatory effects unrelated to its actions on nerves that could have accounted for the observed beneficial effects. However, their observation that a substance $P$ receptor antagonists (NK-1) was capable of reducing granulocyte infiltration into the colon in this model supports the hypothesis that the beneficial effects of lidocaine were at least in part attributable to its ability to inhibit neuropeptide release from extrinsic and intrinsic neurons in the intestine (16).

Experimental models have also been used to assess the effects of ablation of sensory afferent neurons on the development of colonic inflammation. Administration of the neurotoxin capsaicin leads to degeneration of sensory afferent neurons. If these neurons, through the release of pro-inflammatory neuropeptides, contribute to the inflammatory process, ablation of the neurons may have anti-inflammatory effects. However, this question has not been thoroughly investigated. Evangelista and Meli (17) reported that prior ablation of sensory afferent neurons with capsaicin resulted in exacerbation of colitis in a rat model. However, one must interpret these data carefully. Capsaicin-sensitive neurons play an important role in modulating mucosal bloodflow through the gastrointestinal tract. By ablating these neurons, an important component of mucosal defence is removed. As the model used by Evangelista and Meli involves intraluminal application of a cytotoxic solution, it is likely that capsaicin-induced ablation of sensory afferent neurons greatly increased the extent of mucosal injury. Another recent publication from the same group suggested that capsaicin could protect the colonic mucosa from injury induced by a cytotoxic solution (18). Co-administration of capsaicin with the agent used to induce colitis (trinitrobenzene sulphonic acid in a vehicle of $50 \%$ ethanol) resulted in a diminution of the extent of mucosal 
injury. One possible explanation for these results is that capsaicin, by activating sensory afferent neurons, increased colonic mucosal bloodflow, thereby increasing the resistance of the colonic mucosa to damage induced by the cytotoxic solution. Thus, in both of the published studies on the effects of capsaicin in experimental colitis, interpretation of the data is made difficult by the possibility that capsaicin administration has an impact on the induction of colitis in the model used. The question of whether or not capsaicin can modulate colonic inflammation has not yet been adequately addressed. Of greatest interest would be a study of the effects of intracolonic capsaicin administration after colitis is established.

\section{COAGULATION AND THROMBOSIS}

The recent work of Wakefield and colleagues $(19,20)$ has stimulated many investigators to re-examine the relationship between coagulation and inflammation as it pertains to the pathogenesis of IBD. Wakefield et al $(19,20)$ suggested that activation of the mesenteric microvascular endothelium is a central step in the development of vasculitis, and that this is an early step in the pathogenesis of Crohn's disease since it is detectable before mucosal inflammation and microscopic ulceration can be seen. Dhillon and co-workers (21) reported the presence of platelet thrombi in a significant proportion of Crohn's disease patients before the development of ulceration. Hudson et al (22) have also demonstrated that mimicking the development of thrombi within the mesenteric circulation, through local injection of microspheres into the submucosal collateral plexus of the ferret, led to the development of intestinal injury which was histologically similar to that seen in Crohn's disease.

For decades there have been reports of a hypercoagulable state in IBD and a relatively high incidence of thromboembolism. For example, clinical thromboembolic complications have been reported in 2 to $4 \%$ of patients with IBD (23), and in one postmortem study, evidence of thromboembolism was found

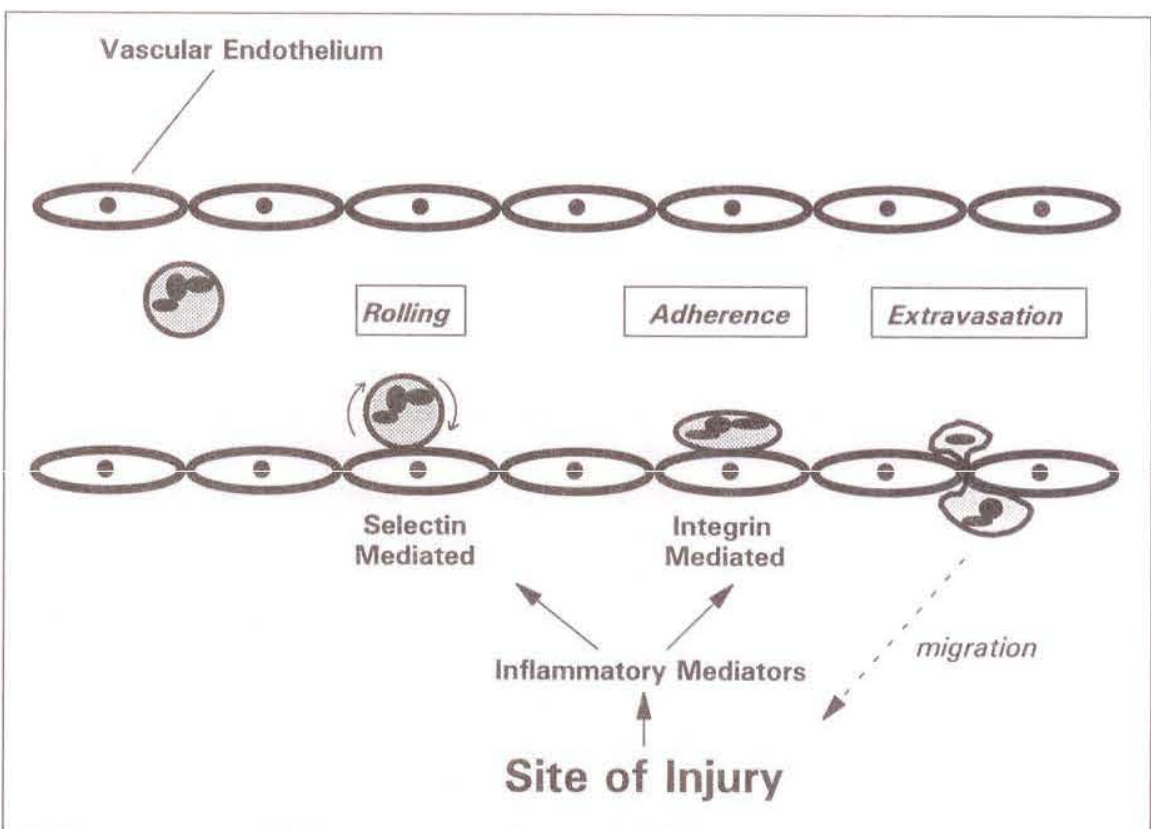

Figure 2) Leukocyte rolling, adherence and emigration in response to an inflammatory signal. Rolling of leukocytes is mediated by 'selectins' on the endothelium and the leukocyte. Adherence and possibly emigration are mediated by adhesion molecules on the leukocyte and on the endothelium

in $39 \%$ of IBD cases (24). Active Crohn's disease has been associated with elevated levels of plasma fibrinogen, factors $\mathrm{V}$ and VIII and platelet count, suggesting a hypercoagulable state $(25-27)$. Hudson et al (28) reported elevated levels of many prothrombotic factors (fibrinopeptide A, prothrombin fragments) in the blood of Crohn's disease patients. There is also evidence of impaired fibrinolysis in IBD (29-31). Lam et al (26) reported low antithrombin III levels in IBD patients and noted that even a modest decrease in blood levels of this factor is considered a risk for thromboembolism. Taken together, the data from these studies and numerous others suggest that a disorder of coagulation may contribute to the pathogenesis of IBD.

In addition to its central role in thrombosis, the platelet is increasingly being recognized as an important inflammatory cell. There is evidence for the involvement of platelets in the thromboembolic disorders reported in IBD patients. Webberley and associates (32) recently reported that in a study of 104 patients with IBD (eight of whom had previously had thromboembollsm), $30 \%$ had spontaneous platelet aggrega- tion and a further $20 \%$ exhibited a hypersensitivity to low concentrations of aggregating agents. Plasma thromboxane and beta-thromboglobulin levels were also significantly elevated, suggesting activation of platelets.

The difficulty in interpreting these studies of platelet function in IBD is that it is not clear whether these changes predated the development of IBD or occurred as a consequence of IBD. It is also difficult to assess the contribution of these changes to the pathogenesis of IBD and the development of tissue injury. Moreover, the use of various antiinflammatory drugs by the IBD patients may have contributed to the observed changes in platelet function.

A recent clinical trial suggested that the coagulative disorders associated with IBD may indeed contribute to the disease process and the development of symptoms. Gaffney et al (33) reported improvement in 10 ulcerative colitis patients treated with anticoagulant doses of heparin; nine patients were poorly controlled on sulfasalazine and prednisolone, while the other was not taking medication. The patients selfadministered heparin daily and continued to take sulfasalazine, while the prednisolone was tapered to a stop. 
Nine patients became asymptomatic, and the other had persistent symptoms but with a $40 \%$ reduction in severity. Paradoxically, rectal bleeding decreased during heparin therapy.

It is important to note that heparin can exert anti-inflammatory effects and influence endothelial function through mechanisms unrelated to its anticoagulant properties (34). Evidence that heparin can block anaphylactic reactions dates back to the 1920s (35). Seeds et al (36) reported anti-inflammatory effects of heparin on allergen or PAF-induced eosinophil infiltration of the guinea pig lung. Interestingly, these effects were observed with a low molecular weight heparin-like molecule which did not exert anticoagulant effects, but not with polyglutamic acid or high molecular weight dextrans that share heparin's polyanionic property.

\section{ADHESION MOLECULES}

Infiltration of the intestinal mucosa by neutrophils, macrophages, lymphocytes and other leukocytes is a hallmark feature of IBD. Moreover, this infiltration almost certainly accounts for a significant amount of the mucosal injury associated with IBD. The movement of leukocytes from the bloodstream into a tissue occurs in several steps (Figure 2). The leukocyte first leaves the main flow of blood and begins to roll along the vascular endothellum. Next, the leukocyte becomes firmly adherent to the endothelium. The leukocyte then slowly migrates to the junction between adjacent endothelial cells and begins to crawl through this junction and into the underlying tissue. Each of these steps in leukocyte emigration involves tightly regulated interactions between specific adhesion molecules on the leukocyte and the endothelium. By interfering with these interactions, it is possible to inhibit the movement of leukocytes from the bloodstream to an inflamed tissue, and in doing so, to reduce the extent of tissue injury.

Rolling of leukocytes along the endothelium is mediated by a group of adhesion molecules called 'selectins'. These molecules have carbohydrate domains that are critical to their function in mediating intercellular adhesive interactions. The selectins on leukocytes are not yet completely characterized. 'Eselectin' and 'P-selectin' are examples of selectins expressed on the surface of vascular endothelial cells. It is possible to inhibit leukocyte rolling on the endothelium by administering monoclonal antibodies directed against these molecules (37). If leukocytes are prevented from rolling on the endothelium, firm adherence and migration out of the vessel are also prevented.

Firm adherence of leukocytes to the endothelium is mediated by another group of adhesion molecules. On the endothelium, these molecules include immunoglobulins such as intercellular adhesion molecule- 1 and -2 (ICAM- 1 and -2 , respectively) and vascular cell adhesion molecule-1 (VCAM-1). There are numerous adhesion molecules on the leukocytes that bind to the endothelial adhesion molecules. For example, the principal group of adhesins on neutrophils are the integrins CDII/ CD18. Adherence and subsequent emigration of leukocytes can be blocked by monoclonal antibodies directed against the integrins or against the endothelial adhesion molecules. Such antibodies have been tested in experimental models of intestinal inflammation. For example, the increased epithelial permeability associated with a rabbit model of colitis could be reduced by approximately $70 \%$ by treating the animals with an antibody directed against CD18 (38). This antibody completely suppressed granulocyte infiltration into the mucosa. These data support the hypothesis that granulocyte recruitment into the mucosa and across the epithelium accounts for a significant portion of epithelial injury. Podolsky and coworkers (39) recently reported dramatic beneficial effects of treatment of colitis in cotton-top tamarins with an antibody directed against an adhesion molecule found on monocytes and lymphocytes (very low antigen [VLA]-4).

While adhesion molecules represent a relatively new target for anti-inflammatory drug development, many of the anti-inflammatory drugs that have been in use for decades exert at least part of their beneficial actions through effects on adhesion molecule expression. For example, glucocorticoids inhibit the expression of a number of adhesion molecules, including ICAM-1 and E-selectin (40). Indeed, the downregulation of expression of these adhesion molecules by glucocorticoids likely accounts for the well documented observation of leukopenia following administration of these drugs. When expression of ICAM-1 and E-selectin are inhibited, the pool of leukocytes - that under normal conditions are rolling or adherent to the endothelium - become detached and re-enter the circulation. Heparin is another drug that exerts anti-inflammatory properties that may be in part related to effects on adhesion molecules. Nelson et al (41) recently demonstrated that various preparations of heparin could block L-selectin and P-selectin and therefore could block binding of neutrophils to endothelium and platelets.

The development of drugs that will interfere with the function of adhesion molecules is a considerable challenge. While many monoclonal antibodies will block the interactions mediated by these molecules, the use of these substances for treatement of IBD is limited by the need for systemic administration. Moreover, despite attempts to 'humanize' the antibodies, immunogenicity remains a problem, especially when the antibodies have to be administered repeatedly. A further problem is that blockade of the ability of leukocytes to adhere renders the patient more susceptible to infections, although there is evidence that adequate antibiotic coverage during the period of treatment will greatly reduce the risk of infection. Since many of the adhesion molecules, particularly selectins, have carbohydrate residues that are critical to their activity, some pharmaceutical companies are attempting to develop carbohydrate-based drugs that will interfere with leukocyte adherence to these molecules. Attempts are also being made to understand better the signal transduction pathways involved in the regulation of adhesion molecule expression so that this may be a target for modulation of the activity of these molecules. 


\section{SUMMARY}

There are numerous potential targets for anti-inflammatory therapy in IBD. This review focused on only three of these targets. Improvements in antiinflammatory therapy can be achieved in two major ways. First, it may be possible to develop more effective therapies. Second, it may be possible to develop therapies that are equally effective as existing drugs but have a better adverse effect profile. For example, if glucocorticoids produce their desired anti-inflammatory effects through inhibition of expression of adhesion molecules, it should be possible to produce novel molecules that achieve this more effectively and selectively, thereby yielding fewer side effects. On the other hand, it is possible that the anti-inflammatory effects of glucocorticoids are

ACKNOWLEDGEMENTS: Dr Wallace is a Medical Research Council of Canada (MRC) Scientist and an Alberta Heritage Foundation for Medical Research Scentist, supported by grants from the MRC and the Crohn's and Colitis Foundation of Canada.

\section{REFERENCES}

1. Sharon P, Stenson WF, Enhanced synthesis of leukotriene $\mathrm{B}_{4}$ by colonic mucosa in inflammatory bowel disease. Gastroenterology 1984;86:453-60.

2. Wallace JL. 5-Lipoxygenase: A rational target for therapy of inflammatory bowel disease. Trends Pharmacol Sci 1990;11:51-3.

3. Wallace JL. Release of plateletactivating factor (PAF) and accelerated healing induced by a PAF antagonist in an animal model of chronic colitis. Can J Physiol Pharmacol 1988;66:422-5.

4. Ellakim R, Karmell F, Razin E, Rachmilewitz R. Role of plateletactivating factor in ulcerative colitis. Enhanced production during active disease and inhibition by sulfasalazine and prednisolone. Gastroenterology 1988;95:1167-72.

5. Cominelli F, Nast CC, Duchini A, Lee M. Recombinant interleukin-1 receptor antagonist blocks the proinflammatory activity of endogenous interleukin-1 in rabbit immune colitis. Gastroenterology 1992:103:65-71.

6. Sharkey KA. Substance P and calcitonin gene-related peptide (CGRP) in gastrointestinal inflammation. Ann N Y Acad Sci 1992;664:425-42. not attributable to a single action, but to the ability of these drugs to interfere with the inflammatory cascade at many different steps. If this latter possibility is the case, it may be difficult to improve on anti-inflammatory effectiveness and, at the same time, reduce the adverse effect profile.

The anti-inflammatory properties of heparin have been recognized for over 60 years. There is increasing evidence suggesting that the anti-inflammatory and anticoagulant properties of this substance can be separated. There are intriguing preliminary studies suggesting that heparin is very effective in reducing the severity of ulcerative colitis. The novel heparin derivatives that lack anticoagulant activity will be powerful tools to determine to what extent the beneficial

7. Kubota Y, Petras RE, Ottaway CA, Tubbs RR, Farmer RG, Fiocchi C. Colonic vasoactive intestinal peptide nerves in inflammatory bowel disease. Gastroenterology 1992;102:1242-51.

8. Bienenstock J, Croitoru K, Ernst PB, Stanisz AM. Nerves and neuropeptides in the regulation of mucosal immunity. Adv Exp Med Biol 1990;257:19-26.

9. Shananan F, Denburg JA, Fox K, Bienenstock J, Befus D. Mast cell heterogeneity: effects of neuroenteric peptides on histamine release. J Immunol 1985;135:1331-7.

10. Felton DL, Felton SY, Carlsson SL, Olschowka JA, Livnat S.

Noradrenergic and peptidergic innervation of lymphoid tissue. J Immunol 1985;135:755-65.

11. Kyosola K, Penttila O, Salaspuro M. Rectal mucosal adrenergic innervation and enterochromaffin cells in ulcerative colitis and irritable colon. Scand J Gastroenterol 1977;12:363-7.

12. Mantyh CR, Gates TS, Zimmerman RP, et al. Receptor binding sites for substance $P$, but not for substance $K$ or neuromedin $\mathrm{K}$, are expressed in high concentrations by arterioles, venules, and lymph nodules in surgical specimens obtained from patients with ulcerative colitis and Crohn's disease. Proc Natl Acad Sci 1988;85:3235-9.

13. McHugh K, Weingarten HP, Khan I, Riddell R, Collins SM. Stress-induced exacerbation of experimental colitis. Gastroenterology 1993;104:A803. (Abst)

14. Wood JD, Peck OC, Sharma HM, et al. Stress induced inflammatory changes in the colon of the cotton-top tamarin model for spontaneous colitis effects of heparin are attributable to its anticoagulant effects.

Evidence for a neural component of the pathogenesis of IBD, while primarily anectdotal in nature, is still compelling. In particular, there is a wealth of data suggesting that the central and enteric nervous systems can markedly alter mucosal immune function. The demonstration of the effectiveness of lidocaine enemas in the treatment of proctitis is fascinating, but these studies need to be repeated in a more controlled manner (recognizing that a placebo control may not be feasible). Specific receptor antagonists for many of the neuropeptides are becoming available and should prove to be useful for dissecting the contribution of some of these mediators to the inflammatory response in IBD.

and colon cancer. Gastroenterology 1993; 104:A803. (Abst)

15. Björck S, Dahlström A, Johansson L, Ahlman H. Treatment of the mucosa with local anaesthetics in ulcerative colitis. Agents Actions 1992;35(Suppl):C60-72.

16. McCafferty DM, Sharkey KA, Wallace JL. Beneficial effects of local and systemic lidocaine in experimental colitis. Am J Physiol 1994:266:G560-7.

17. Evangelista S, Meli A. Influence of capsaicin-sensitive fibres on experimentally-induced colitis in rats. J Pharm Pharmacol 1989:41:574-75.

18. Goso C, Evangelista S, Tramontana M, Manzini S, Blumberg PM, Szallasi A. Topical capsaicin administration protects against trinitrobenzene sulfonic acid-induced colitis in the rat. Eur J Pharmacol 1993;249:185-90.

19. Wakefield AJ, Sankey EA, Dhillon AP, et al. Granulomatous vasculitis in Crohn's disease. Gastroenterology 1991;100:1279-87.

20. Wakefield AJ, Sawyerr AM, Dhillon AP, et al. Pathogenesis of Crohn's disease: multifocal gastrointestinal infarction. Lancet 1989;ii:1057-62.

21. Dhillon AP, Anthony A, Sim R, et al. Mucosal capillary thrombi in rectal biopsies. Histopathology 1992;21:127-33.

22. Hudson M, Plasecki C, Sankey EA, et al. A ferret model of acute multifocal gastrointestinal infarction. Gastroenterology 1992;102:1591-6.

23. Talbot RW, Heppell I, Dozois RR, Beart RW. Vascular complications of inflammatory bowel disease. Mayo Clin Proc 1986;61:140-5.

24. Graef V, Baggenstoss AH, Sauer WG, 
Spittell JL. Venous thrombosis occurring with nonspecific ulcerative colitis. Arch Intern Med 1966;117:277-82.

25. Lake AM, Stauffer JQ, Stuart M]. Haemostatic alterations in inflammatory bowel disease. Am J Dig Dis 1978;23:897-902.

26. Lam A, Borda LT, Inwood MJ, Thompson S. Coagulation studies in ulcerative colitis and Crohn's disease. Gastroenterology 1975;68:245-51.

27. Lee JCL, Spittell J, Sauer WG, Owen CA, Thompson JH.

Hypercoagulability associated with chronic ulcerative colitis: changes in blood coagulation factors. Gastroenterology 1968;54:76-84.

28. Hudson M, Hutton RA, Wakefield AJ, Sawyerr AM, Pounder RE. Evidence of activation of coagulation in Crohn's disease. Blood Coagul Fibrinolysis 1992;3:773-8.

29. Conlan MG, Haire WD, Burnett DA. Prothrombotic abnormalities in inflammatory bowel disease. Dig Dis Sci 1989;34:1089-93.

30. de Bruin PAF, Crama-Bohbouth G, Verspaget HW, et al. Plasmogen activators in the intestine of patients with inflammatory bowel disease.

Thromb Haemost 1988;60:262-6.

31. Gris JC, Schved JF, Raffanel C, et al. Impaired fibrinolytic capacity in patients with inflammatory bowel disease. Thromb Haemost 1990;63:472-5.

32. Webberley MJ, Hart MT, Melikian V. Thromboembolism in inflammatory bowel disease: role of platelets. Gut 1993;34:247-51.

33. Gaffney PR, Doyle CT, Hogan I, Gaffney A. Paradoxical response to heparin in 10 patients with ulcerative colitis. Gastroenterology 1993;104:A703. (Abst)

34. D'Amore PA. Heparin-endothelial cell interactions. Haemostasis 1990;20(Suppl 1):159-65.

35. Van der Carr RF, Williams OB. Further studies on the influence of heparin on anaphylactic shock in the guinea pig. J Immunol 1928;15:13-20.

36. Seeds EAM, Hanss J, Page CP. The effect of heparin and related proteoglycans on allergen and PAF-induced eosinophil infiltration. J Lipid Mediat 1993; 7:269-78.

37. Mulligan MS, Watson SR, Fennie C, Ward PA. Protective effects of selectin chimeras in neutrophil-mediated lung injury. J Immunol 1993;151:6410-7.

38. Wallace JL, Higa A, McKnight GW, MacIntyre DE. Prevention and reversal of experimental colitis by a monoclonal antibody which inhibits leukocyte adherence. Inflammation 1992;16:343-54.

39. Podolsky DK, Lobb R, King N, et al. Attenuation of colitis in the cotton-top tamarin by anti- $\alpha 4$ integrin monoclonal antibody. J Clin Invest 1993;92:372-80.

40. Cronstein BN, Kimmel SC, Levin RI, Martiniu, F, Weissmann G. A mechanism for the antiinflammatory effects of corticosteroids: the glucocorticoid receptor regulates leukocyte adhesion to endothelial cells and expression of endothelialleukocyte adhesion molecule $I$ and intercellular adhesion molecule 1. Proc Natl Acad Sci USA 1992;89:9991-5.

41. Nelson RM, Cecconi O, Roberts WG, Aruffo A, Linhardt RJ, Bevilacqua MP. Heparin oligosaccharides bind $\mathrm{L}$ - and $\mathrm{P}$-selectin and inhibit acute inflammation. Blood 1993;82:3253-8. 


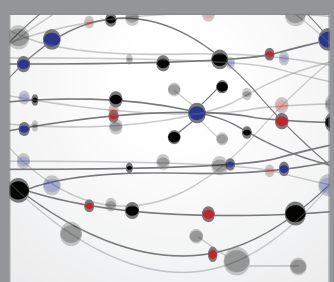

The Scientific World Journal
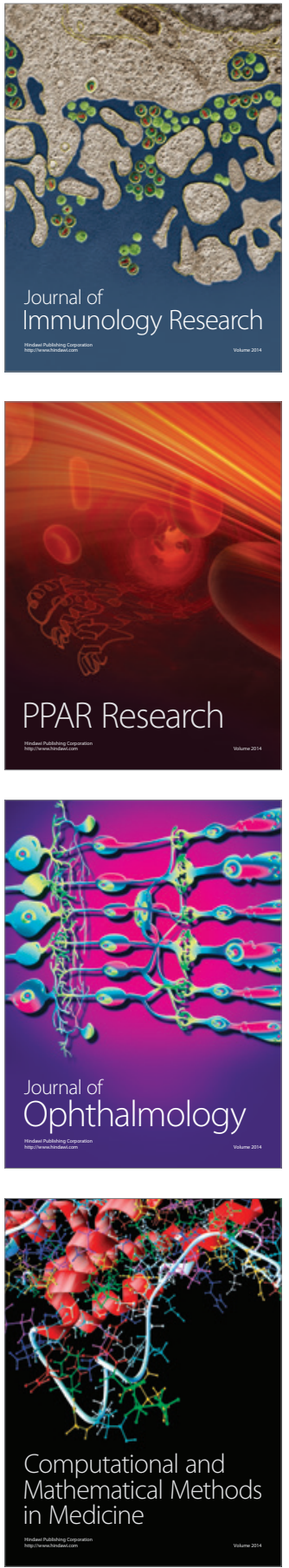

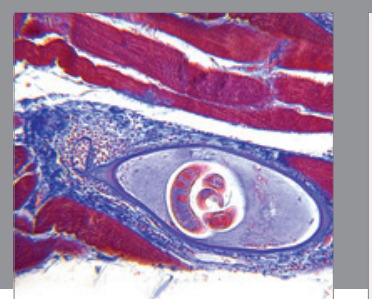

Gastroenterology Research and Practice

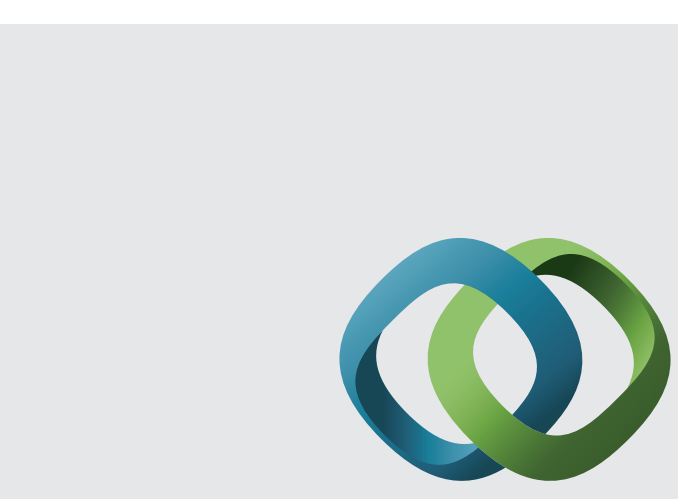

\section{Hindawi}

Submit your manuscripts at

http://www.hindawi.com
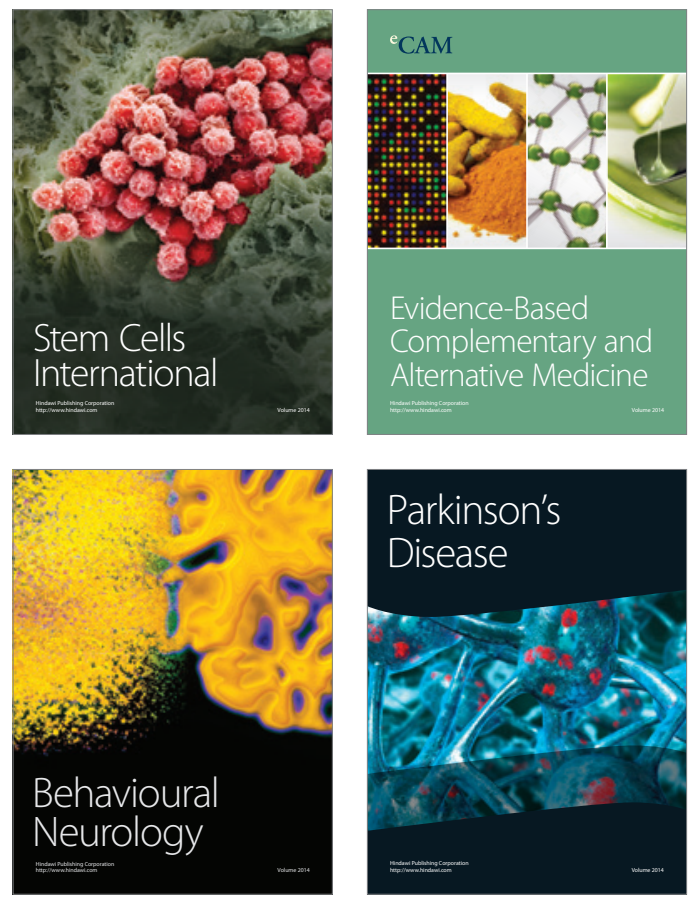
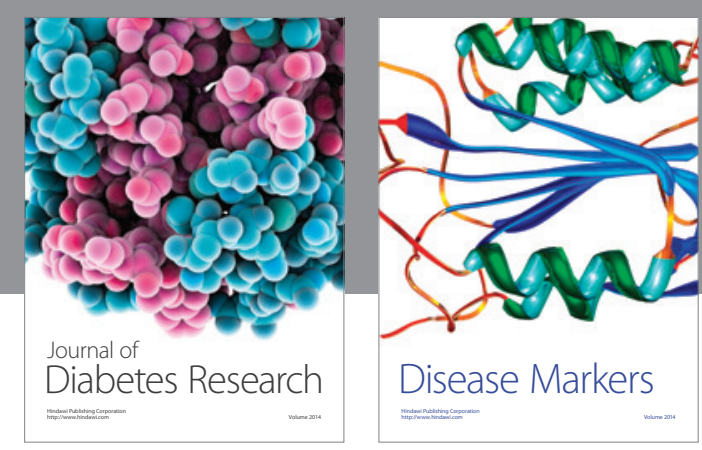

Disease Markers
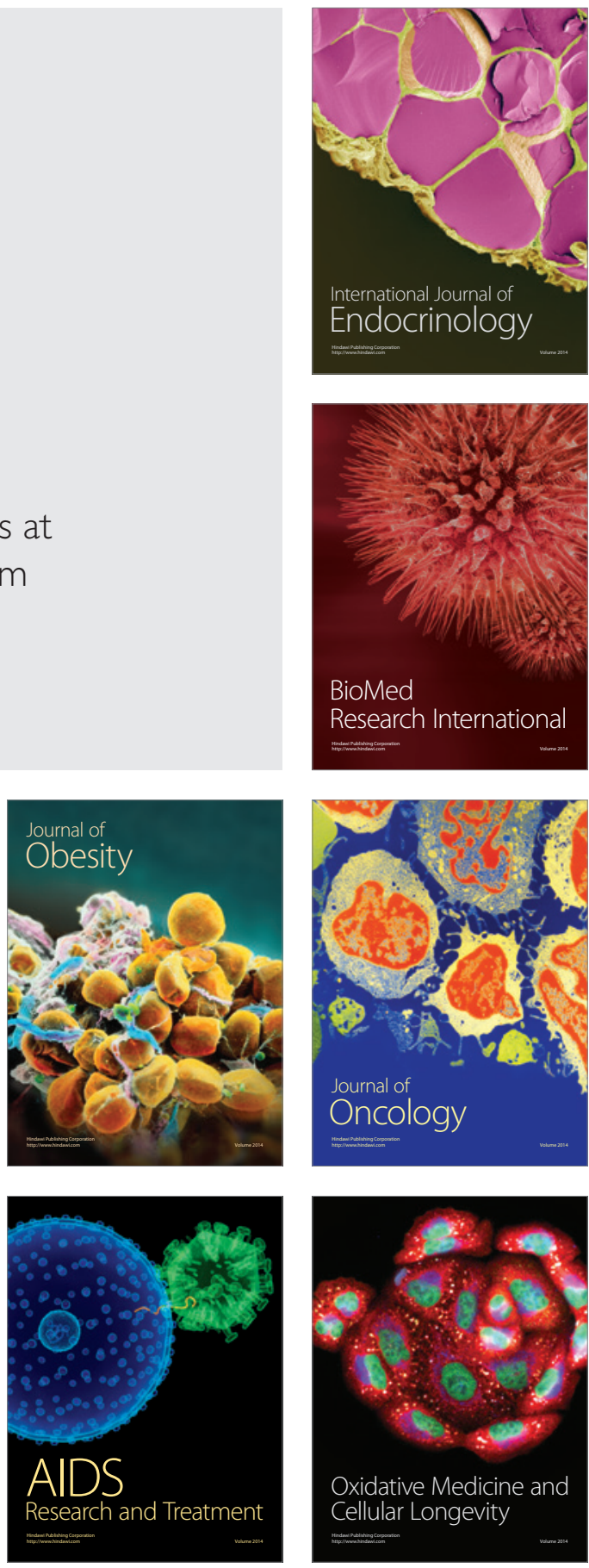